IFN Working Paper No. 666, 2006

\title{
Investment Liberalization \\ - Why a Restrictive Cross-Border Merger Policy can be Counterproductive
}

Pehr-Johan Norbäck and Lars Persson 


\title{
Investment liberalization - why a restrictive
}

\section{cross-border merger policy can be counterproductive}

\author{
Pehr-Johan Norbäck* \\ Research Institute of Industrial Economics
}

Lars Persson

Research Institute of Industrial Economics and CEPR

June 13, 2006

\begin{abstract}
Investment liberalizing countries are often concerned that cross-border mergers $\&$ acquisitions, in contrast to greenfield investments, might have an adverse effect on domestic firms and consumers. However, given that domestic assets are sufficiently scarce, we identify a preemption effect and an asset complementarity effect, which imply that the acquisition price is significantly higher than the domestic seller's profits. Moreover, we show that for the acquisition to take place, the MNE must be sufficiently efficient when using the domestic assets, otherwise rivals will expand their business, thereby making the acquisition unprofitable. Consequently, restricting cross-border M\&As may also hurt consumers.

Keywords: Investment Liberalization, Mergers \& Acquisitions, Development, Ownership. JEL classification: F23, K21, L13, O12
\end{abstract}

*This paper is a substantially revised version of Norbäck and Persson (2002). We have benefitted from useful comments from Jonas Björnerstedt, Henrik Braconier, Massimo Motta, Peter Neary and participants in seminars at Bergen University, European University Institute in Florence, IUI in Stockholm, Purdue University, Southern Methodist University, University of Colorado at Boulder, University College Dublin, University Pompeu Fabra, and the International M\&As conference in Paris, 2004. Financial support from the Marianne and Marcus Wallenberg Foundation, and Tom Hedelius' and Jan Wallander's Research Foundations, is gratefully acknowledged. Email: larsp@iui.se. 


\section{Introduction}

In the last decade, we have witnessed a strong trend of investment liberalizations in developing and transition countries. Despite the generally welcoming attitude towards inward Foreign Direct Investment (FDI) among investment liberalizing countries ${ }^{1}$, concerns are raised about the impact of cross-border mergers and acquisitions (M\&As) on development. ${ }^{2}$ One such concern is that underdeveloped equity markets or financial crises allow foreign entrants to acquire domestic firms at "too low" a price. There is also a concern that cross-border M\&As, in contrast to greenfield FDI (investment in new capital), do not increase the productive capacity and might lead to lower consumer welfare and layoffs. ${ }^{3}$ Indeed, some countries restrict the right of foreign individuals and firms to acquire domestic firms, or apply special restrictions to foreign firms in certain industries. ${ }^{4}$

The purpose of this paper is to study the impact on the host country of different liberalization programs with respect to cross-border M\&As, by comparing two different liberalization programs: (i) allowing greenfield investments but not cross-border M\&As (referred to as a discriminatory policy) or (ii) allowing greenfield investments and crossborder M\&As (referred to as a non-discriminatory policy).

\footnotetext{
${ }^{1}$ In the early 1990s, the value of inward FDI in developing countries was about $\$ 50$ billion and in the late 1990s, it exceeded $\$ 200$ billion. FDI today accounts for a large share of capital formation in these countries, and FDI inflows as a percentage of private capital formation in all industries have increased from $6.7 \%$ in 1990 to $17.7 \%$ in 1998. The corresponding values for Central and Eastern Europe were 0.79\% in 1990 and 16.2 \% in 1998, see WIR 2000.

2 The value of cross-border M\&As in developing countries has been growing rapidly since the mid-1990s and constitutes about one third of the FDI inflows in this period. The developing countries' share of world cross-border M\&As increased from $2 \%$ in 1987 to almost $9 \%$ in 1999 (WIR, 2000).

${ }^{3}$ WIR 2000.

${ }^{4}$ This is the case in Malaysia and the Republic of Korea, for example. But the practise of countries in this respect has also changed over time. For instance, by May 1998, restrictions on foreign acquisitions of domestic shares in the stock market, and restrictions on M\&As by foreigners in the Republic of Korea had been abolished. However, the new investment policy still favors greenfield investment through, for instance, different tax treatments of M\&A investments (WIR, 2000).
} 
To this end, we make the following distinction between entry by acquisition and greenfield entry: the domestic assets are in scarce supply and the price is determined in an auction acquisition game. The limited availability of these assets may be associated with the acquired firm having privileged access to the distribution system, ownership of land or permits, knowledge of the specific characteristics of the local market, locally well-known brand names, or assets already in the market allowing early entry. ${ }^{5}$ The variable cost of greenfield investment (new investments) is, on the other hand, assumed to be fixed. This is motivated by the fact that the supply of inputs (labor and capital) used in these investments to a large extent consists of inputs used in many other industries in the economy and the investor in a particular industry could then be seen as a price taker.

To capture these aspects, we consider a model where a domestic firm is initially located in the market in the host country, $\mathrm{H}$. There are also several multinational enterprises (MNEs) located in the world market. The market in the host country will now be exposed to international competition. In the first stage, the MNEs might acquire the domestic firm's assets under the non-discriminatory policy, whereas no cross-border acquisition is allowed under the discriminatory policy. In the second stage, firms have the option of investing in new assets in country H. New investments are labelled greenfield investments for non-acquiring MNEs, and sequential investments for the acquiring MNE (if a sale occurs) and the domestic firm (if no sale occurs). Finally, in the third stage, firms compete in oligopoly fashion in the product market in country $\mathrm{H}$.

It is straightforward to identify circumstances, not modeled in this paper though, under which MNEs might acquire domestic firms at "too low" a price when bargaining between the acquiring MNE and the seller takes place in isolation. The MNE may then, for instance, use informational or financial advantages in the bargaining, thereby acquiring the domestic firm at a price substantially below its "market value". In contrast, we show that

${ }^{5}$ This seems to be in line with the discussions in the business literature, where it is claimed that the main motivation for choosing M\&As over greenfield investments is that the buyer then quickly obtains unique assets (WIR 2000). 
the acquisition price is higher than the domestic firm's profits under the discriminatory policy when there are several potential MNE-buyers due to the bidding competition over the domestic target firm.

The first reason is a profit asset complementarity effect. It is likely that the domestic assets are more efficiently used when transferred from domestic to foreign ownership, since MNEs are typically firms with strong firm-specific assets in terms of strong technology, know-how of marketing, organization etc. ${ }^{6}$ These firm-specific assets could be combined with the domestic firm's locally strong assets, such as distribution network, access to specific assets like permits, etc. If this asset complementarity effect is sufficiently large, a surplus is created when the domestic assets are transferred to an MNE. However, due to the bidding competition between the MNEs for buying these assets, this entire surplus is captured by the target firm, i.e. the domestic firm. The second effect is a preemption effect, which is only present in oligopolistic interaction. If the domestic assets are more efficiently used by an MNE, it is likely that the profit of a non-acquiring MNE will decrease when the assets are transferred from domestic to foreign ownership, which implies that the MNE gains from preventing other MNEs from obtaining the assets. Once more, due to the bidding competition between MNEs, this entire surplus is captured by the domestic firm. Note that this second effect implies that the selling domestic firm captures a larger surplus than the surplus created by its buyer as compared to the situation where the assets would exit. This is due to the fact that the seller is not only paid for selling its assets to the acquiring MNE but also for not selling to a rival MNE.

Moreover, it is shown that under the discriminatory policy, the domestic firm might be forced out of the market due to competition from the potentially more efficient greenfield entering MNEs. However, the domestic assets might be valuable for the MNEs and a cross-border M\&A would take place if allowed. A restrictive cross-border M\&A policy

\footnotetext{
${ }^{6}$ Indeed, FDI is considered to be an important channel for transferring new technology and knowledge into developing and transition countries (see, Caves (1996) or Markusen (1995)). Lipsey (2000) argues that, more generally, one of the major functions of FDI is to transfer assets from less efficient to more efficient owners and managers.
} 
might thus cause the exit of domestic producers, i.e. an exit without any compensation. Consequently, by allowing cross-border M\&A, domestic owners can actually capture part of MNE industry rents, i.e. rents that under a discriminatory policy would only be captured by MNEs, and which can be used in different sectors in the domestic economy.

The bidding competition over Banco do Estado de Sao Paulo (Banespa), the seventh largest bank in Brazil, is an example where the competition between different MNEs over strategic important assets seems to have generated large rents for the selling domestic firm. In November 2000, Banco Santander Central Hispanio (BSCH) won a controlling minority stake in Banespa, in competition with several other large banks, including its Spanish rival Banco Bilbao Vizcaya Argentaria (BBVA). According to Business Week (April 23, 2001): "It cost an astronomical $\$ 3.55$ billion, but it put BSCH back on top" (before BBVA authors' comment). The assets of Banespa were considered to be strategically valuable, as indicated by the following quote "Anyone who can add Banespa to their existing structure will take a gigantic leap forward," says Elio Duarte, director of institutional relations at the Brazilian subsidiary of Britain's HSBC Holdings PLC, one of the nine banks qualified to take part in the auction." (Business Week, November 20, 2000). According to Business Week (November 20, 2000), this means that "...bidders will pay a premium not just to get their hands on Banespa but also to stop rivals from doing so."

The second concern about cross-border M\&As addressed in this paper is that, in contrast to greenfield FDI, they do not increase the productive capacity in the country and thus, are not beneficial to consumers and labor. We show that the amount of productive capacity in the market might, indeed, be lower under the non-discriminatory policy, due to the acquisition of the domestic firm. Thus, welfare decreasing acquisitions can take place in equilibrium, i.e. acquisitions by foreign owners that will use the domestic assets less efficiently and acquire the domestic assets for market power reasons. However, it is also shown that for the acquisition to take place, the MNE must be sufficiently efficient when using the domestic assets, i.e. there is a lower limit on how inefficient a foreign acquirer 
can be. ${ }^{7}$

To see this, note that an acquisition mainly driven by the desire to eliminate a rival to be able to increase product market prices will imply that rivals in the market will have an incentive to expand their business. However, this reaction by the rivals' will reduce the profitability of the acquisition. Hence, the acquiring firm must be sufficiently efficient in using the domestic assets to counter an expansionary reaction by its rivals to make the acquisition profitable. This implies that there is a counteracting effect to the concentration effect (the domestic firm being bought out), which tends to decrease total capital in the industry, namely an investment efficiency effect which tends to increase the total capital in the industry.

Using a Linear-Quadratic Model with asset complementarities and endogenous capital investment, we then illustrate that the amount of productive capacity in the market will be higher under the non-discriminatory policy when the asset complementarity between domestic and foreign assets is sufficiently high and consequently, consumers and labor also gain when foreign acquisitions are allowed. The reason is that when the assets' complementarity is high, the acquiring firm will become more aggressive in its investment behavior and increase its sequential investment to such an extent that total investment in the market increases, despite the reduced greenfield investments by non-acquiring MNEs following the acquirer's expansion. Conversely, it is also in such situations, with large sequential investments by the acquiring MNE and repressed investments by non-acquiring MNEs, where the bidding competition over the benefits of becoming a strong acquirer and avoiding becoming a weak non-acquirer leads to a substantially higher acquisition price than the domestic firm's reservation price. Consequently, we demonstrate that asset complementarities in acquisitions and the associated dynamic investment effects are important for determining the welfare effects of a cross-border M\&As.

The related theoretical literature on FDI and MNEs is surveyed in e.g.Markusen (1995).

${ }^{7}$ Evidence from developing countries shows that sequential investment after cross-border M\&As can be sizeable (WIR (2000). 
This literature seems to largely focus on greenfield investment, even though some results are not specific to the mode of entry. But there is no systematic analysis of the differences in welfare ramifications of allowing different modes of entry such as greenfield investment and/or acquisition of assets already in the market. ${ }^{8}$ There is also a small theoretical literature addressing welfare aspects of cross-border mergers in international oligopoly markets. ${ }^{9}$ But this literature typically treats the greenfield investment alternative cursory. This paper can be said to bridge these two bodies of literature, by analyzing a model that treats both entry modes much more symmetrically. ${ }^{10}$ In this model both the acquisition price and the size of new investments (greenfield and sequential investments) are endogenously determined. This enables us to determine the long run effects of allowing cross-border mergers and acquisitions, that is, we also take into account the implications of merger regime for the dynamic investments (greenfield and sequential investments). In the policy debate, these effects have often been suggested to be very significant, but they have so far been neglected in the economic literature.

The model is spelled out in Section 2. In Section 3, we derive the equilibrium ownership structure. Section 4.1 studies the effects on producer surplus of the different specified merger policies, whereas Section 4.2 studies the effects on investments and aggregate capital levels. In Section 4.3, more specific results are derived in a Linear-Quadratic Model with asset complementarities and endogenous capital investment. Section 5 is an extension section where we examine effects of endogenous entry and exit, and effects of having more domestic firms in the host market. Section 6 concludes.

${ }^{8}$ See Markusen (1997) for a study of the effects of investment liberalization on FDI.

9 This literature includes papers by, for example, Falvey (1998), Head and Reis (1997), Horn and Persson (2001a), Lommerud, Straume and Sorgard (2004), and Neary (2003) and Norbäck and Persson (2004).

${ }^{10}$ Exceptions are Mattoo, Olarrega, and Saggi (2004 and Klimenko and Saggi (2005). They study how entry mode affects welfare in markets where foreign technology transfers are possible. However, by using a framework with only one foreign firm they abstract from the competitive bidding over the domestic firm which is central in our approach. 


\section{The Model}

Consider a host country, $H$, where the market has previously been served by a single domestic firm, denoted $d$, possessing one unit of domestic assets, denoted $\bar{k}$. This market will now be exposed to international competition ${ }^{11}$.

We assume there to be $M$ MNEs in the world market. The MNEs do not initially have any assets in Country $\mathrm{H}$, but might now invest. The interaction takes place in three stages. In the first stage, the MNEs might acquire the domestic firm's assets under the non-discriminatory policy. Under the discriminatory policy, no acquisitions are allowed. In the second stage, firms can invest in new assets in country H. Finally, in the third stage, firms compete in oligopoly fashion in country H. ${ }^{12}$

The next sections describe the product market interaction, the greenfield investment game, and the acquisition game.

\subsection{Period three: product market interaction}

he firm profits will depend on the distribution of asset ownership, given from the investment game in period 2 , and the acquisition game in period 1 . To capture this, we will work with the following notation: Let the set of firms in the industry be $\mathcal{I}=\{d, 1,2, . . M\}$, and let the set of (potential) ownerships of the domestic assets, $k_{0}$, be $\mathcal{L}=\{d, 1,2, . . M\}$. The asset ownership structure $\mathbf{K}=\left(k_{d}, k_{m_{1}, \ldots}, k_{m_{M}}\right)$ specifies the asset ownership of each firm.

\footnotetext{
${ }^{11}$ There are different reasons why the market is open to international investments now. The country might be investment liberalizing, the international expansion of MNEs might be a natural step in the life cycle of a product or stem from increasing local demand, or the administrative costs of cross-border acquisitions and greenfield entry may have been reduced in the globalization process.

12 The choice of timing between the acquisition and the greenfield investment is not obvious in a general setting. In this particular application, however, it seems natural for the acquisition decision to be made before the greenfield decision, since the assets for sale already exist in the market and entering greenfield requires the construction of a new plant, which is usually time consuming.
} 
The first entry refers to firm d's asset holdings, the second to MNE 1's assets holdings, etc.

$\pi_{i}(\mathbf{x}, \boldsymbol{\kappa}, l)$ denotes the product market profit of firm $i$, where $\mathbf{x}=\left(x_{d}, x_{m_{1}, \ldots,}, x_{m_{M}}\right)$ is the vector of actions taken by firms in the product market interaction in period three, $\boldsymbol{\kappa}=\left(\kappa_{d}, \kappa_{m_{1}, \ldots}, \kappa_{m_{M}}\right)$ denotes the vector of investments in new assets from period two and $l$ denotes the ownership of the domestic assets, given from the acquisition game in period one.

We are now set to describe optimal behavior in the product market interaction. Given the investments in period two, $\boldsymbol{\kappa}$, and the ownership of the domestic assets given from period one, $l$, firm $i$ chooses an action $x_{i} \in R^{+}$to maximize its period-three product market profit, denoted $\pi_{i}\left(x_{i}, x_{-i}: \boldsymbol{\kappa}, l\right)$, where $x_{-i}$ is the set of actions taken by $i$ 's rivals. We may consider the action $x_{i}$ as setting a quantity or a price, as will be shown in later sections. Furthermore, we assume there to exist a unique Nash-Equilibrium, $\mathbf{x}^{*}(\boldsymbol{\kappa}, l)$, defined as:

$$
\pi_{i}\left(x_{i}^{*}, x_{-i}^{*}: \boldsymbol{\kappa}, l\right) \geq \pi_{i}\left(x_{i}, x_{-i}^{*}: \boldsymbol{\kappa}, l\right), \quad \forall x_{i} \in R^{+} .
$$

From (2.1), we can define a reduced-form product market profit for a firm $i$, taking as given the ownership $l$ of the domestic assets $\bar{k}$ and the vector of new investments $\boldsymbol{\kappa}$, as $\pi_{i}(\boldsymbol{\kappa}, l) \equiv \pi_{i}\left(x_{i}^{*}(\boldsymbol{\kappa}, l), x_{-i}^{*}(\boldsymbol{\kappa}, l), \boldsymbol{\kappa}, l\right)$.

\subsection{Stage two: investment in new assets}

In stage two, firm $i$ invests in new assets $\kappa_{i}$, given the ownership $l$ of the domestic assets,

$\bar{k}$, determined in the acquisition game in period one. This investment can be in capacity, $\mathrm{R} \& \mathrm{D}$ or marketing, for instance. Firm $i$ makes its choice $\kappa_{i} \in R^{+}$to maximize the reduced-form product market profit, $\pi_{i}(\boldsymbol{\kappa}, l)$, which we rewrite as $\pi_{i}\left(\kappa_{i}, \kappa_{-i}: l\right)$, where $\kappa_{-i}$ denotes investments in new assets by $i$ 's rivals. We assume there to exist a unique Nash-Equilibrium, $\boldsymbol{\kappa}^{*}(l)$, defined as:

$$
\pi_{i}\left(\kappa_{i}^{*}, \kappa_{-i}^{*}: l\right) \geq \pi_{i}\left(\kappa_{i}, \kappa_{-i}^{*}: l\right), \quad \forall \kappa_{i} \in R^{+}
$$


This allows us to define $\left.\pi_{i}(l) \equiv \pi_{i}\left(\boldsymbol{\kappa}^{*}(l), l\right) \equiv \pi_{h}\left(\mathbf{x}^{*}\left(\boldsymbol{\kappa}^{*}(l)\right), \boldsymbol{\kappa}^{*}(l), l\right)\right)$ as a reduced-form profit function for firm $i$ under ownership $l$, encompassing the firms' optimal actions in period three, $\mathbf{x}^{*}$, and optimal investments in new assets in period two, $\boldsymbol{\kappa}^{*}$. We here assume $\pi_{i}(l)$ to be strictly positive, an assumption which will be relaxed in Section 5.1.

The assumption that MNEs $1,2, . . M$ are symmetric before the acquisition takes place implies that we need only distinguish between two types of ownerships; domestic ownership $(l=d)$ and foreign $(M N E)$ ownership $(l=m)$. A change from domestic to foreign ownership might imply a different use of the domestic assets, $\bar{k}$. We define $\gamma>0$ as a measure of the complementarity between the domestic assets $\bar{k}$ and MNEs' firm-specific assets, assuming the "effective size" under foreign ownership to be $\gamma \bar{k}$. MNEs are typically leading firms in their respective industries and possess firm-specific knowledge in terms of technology or know-how of organization of production and marketing (see Markusen (1995) and Caves (1995)). It is likely that at least some of this knowledge is transferred under a change of ownership, resulting in a more efficient use of the local assets, $\bar{k}$. This corresponds to a $\gamma$ substantially larger than one in the model. ${ }^{13}$

We can then distinguish between two types of asset ownership structures: $\mathbf{K}(m)$ and $\mathbf{K}(d)$ :

$$
\begin{aligned}
\mathbf{K}(m) & =(0, \gamma \bar{k}+\kappa_{A}^{*}, \underbrace{\kappa_{G}^{*}, \ldots, \kappa_{G}^{*}}_{M-1}), \quad \gamma>0 \\
\mathbf{K}(d) & =(\bar{k}+\kappa_{d}^{*}, \underbrace{\kappa_{G}^{*}, \ldots, \kappa_{G}^{*}}_{M}) .
\end{aligned}
$$

Note that there are three types of firms of which to keep track, $h=\{d, A, G\}$, i.e. the domestic firm $(d)$, an acquiring $\operatorname{MNE}(A)$ and non-acquiring MNEs $(G)$. The non-acquiring MNEs will be referred to as greenfield entrants (since they do not possess any acquired assets $\bar{k}$ and only invest in new assets, $\left.\kappa_{G}^{*}\right)$. The first entry in $\mathbf{K}(l)$ shows the asset ownership of the domestic firm, $d$, the second entry is the asset ownership of the potentially acquiring MNE (MNE 1), and the remaining entries show the asset ownership of the

\footnotetext{
${ }^{13}$ There are many studies confirming that technologies and knowledge are transferred to hostcountries through FDI (see Caves 1995).
} 
symmetric non-acquiring MNEs, i.e. the greenfield entrants). Note that under domestic ownership, there are $M$ MNEs that invest greenfield, whereas under MNE ownership, there is one acquiring MNE and $M-1$ non-acquiring MNEs investing greenfield. Note also that firm $d$ does not invest in new assets when selling its assets, $\bar{k}^{14}$

A change in ownership of existing domestic assets $\bar{k}$ from domestic to foreign ownership is then assumed to affect the profit for a firm of type $h, \pi_{h}(l)$, as follows:

Assumption 1: $\frac{d \pi_{A}(m)}{d \gamma}>0, \frac{d \pi_{G}(m)}{d \gamma}<0, \frac{d \pi_{h}(d)}{d \gamma} \equiv 0, h=\{d, G\}$

Assumption 1 then states that an increase in the complementarity parameter, $\gamma$, increases the acquirer's profit, whereas the profit for a non-acquirer (i.e. greenfield investor) decreases. These profit effects may emerge from direct effects on productivity, or by indirectly affecting firms' optimal actions in the period-one product market game $\left(\mathbf{x}^{*}\right)$, or affecting these actions by affecting firms' investment in new assets in period two $\left(\boldsymbol{\kappa}^{*}\right)$. The size of these effects depends on the strength of the complementarities between MNEs' firm-specific assets and the domestic assets. For example, the combination of an MNE's strong brand name and the acquired firm's knowledge of the market or strength in distribution may provide the acquiring MNE with a strong market position. If the brand name of the domestic assets is locally very strong, the strategic value of the assets will also be high. Or, if the domestic assets are sold at an early stage, the acquirer may gain a strong first-mover advantage, thereby building up a dominant position in the product market. ${ }^{15}$

This set-up and this assumption are compatible with several different investment and oligopoly models: the model by Neary (2002) presented in Section 4.3 and with a version

\footnotetext{
${ }^{14}$ We take this assumption to highlight the effects of the domestic firm being eliminated from the competition in the market. However, allowing the domestic firm to also invest does not change the results, given that it is sufficiently less efficient in investing in new assets, which should be reasonable, given the firm-specific assets possessed by MNEs.

${ }^{15}$ As a specific example, in the retail industry, MNEs acquire local retail chains and combine their advantages of global sourcing with the advantages of the established distribution network. As Greenfield entry does not have this advantage, and it takes more time to build local assets, an acquiring MNE is at an advantage. While having the initial possession over the distribution network, a domestic firm lacks the advantage of global sourcing.
} 
of that model with Bertrand competition in differentiated goods, and with the Perry and Porter (1985) oligopoly model, preceded by an investment game into lumpy investment.

\subsection{Stage one: the acquisition game}

To focus on the bidding competition among MNEs as the determinant of the equilibrium buyer, we assume that firm $d$ cannot make a bid on the MNEs. This assumption might be motivated by the domestic owner being financially weaker or lacking the competence to efficiently run the larger business. Moreover, it is assumed that MNEs cannot make bids on each other's firms, which might be supported in two basic ways in a full merger model. One is to assume the profit of a merged entity to be sufficiently small to imply that no merger takes place between the MNEs. ${ }^{16}$ The second possibility would be to assume that mergers between MNEs would not be permitted by the competition authorities.

The acquisition process is depicted as an auction where $M$ MNEs simultaneously post bids and the domestic firm then either accepts or rejects these bids. Each MNE announces a bid, $b_{i}$, for the domestic firm. $\mathbf{b}=\left(b_{1}, . . b_{i} . ., b_{M}\right) \in R^{M}$ is the vector of these bids. Following the announcement of $\mathbf{b}$, the domestic firm may be sold to one of the MNEs at the bid price, or remain in the ownership of firm $d$. If more than one bid is accepted, the bidder with the highest bid obtains the domestic assets. If there is more than one MNE with such a bid, each such MNE obtains the assets with equal probability. The acquisition is solved for Nash equilibria in undominated pure strategies. There is a smallest amount, $\varepsilon$, chosen such that all inequalities are preserved if $\varepsilon$ is added or subtracted.

We now turn to the firms' valuations of the domestic firm's assets, $\bar{k}$. There are three different valuations which need to be considered:

- $v_{m m}$ is the value for an MNE of obtaining $\bar{k}$, when a rival MNE would otherwise

\footnotetext{
${ }^{16}$ For instance, it has been shown by Kamien and Zang (1990) that the hold up problem in merger formation might lead to no merger taking place in equilibrium, if the initial number of firms is sufficiently large. Moreover, mergers might be non-profitable, since the costs associated with mergers can be substantial, for example due to problems of fusing different company cultures.
} 
obtain $\bar{k}$. The first term shows the profit when possessing $\bar{k}$. The second term shows the profit if a rival MNE obtains $\bar{k}$, in which case the MNE invests greenfield.

$$
v_{m m}=\pi_{A}(m)-\pi_{G}(m)
$$

- $v_{m d}$ is the value for an MNE of obtaining $\bar{k}$, when the domestic firm would otherwise keep them. The profit for an MNE of not obtaining assets $\bar{k}$ is different in this case, due to the change of identity of the firm who would otherwise obtain the assets.

$$
v_{m d}=\pi_{A}(m)-\pi_{G}(d)
$$

- $v_{d}$ is the value for the domestic firm of obtaining $\bar{k}$. By assumption, $\pi_{d}(m)=0$ and thus:

$$
v_{d}=\pi_{d}(d)
$$

\section{The equilibrium ownership structure}

We can now proceed to solve for the Equilibrium Ownership Structure (EOS). The game is solved by backward induction. In period three, firms optimize given the outcome in the acquisition stage and the investment stage, where we have assumed a unique Nash equilibrium $\mathrm{x}^{*}$ to exist in product market actions. In period two, firms invest optimally, given the outcome in the acquisition stage, where we have assumed there to exist a unique Nash equilibrium denoted $\boldsymbol{\kappa}^{*}$ in investments. In period one, the firms' bidding behavior is dependent on the relation between their own valuation of obtaining assets $\bar{k}$ and all other firms' valuations of obtaining these assets. Since MNEs are symmetric, valuations $v_{m m}$, $v_{m d}$ and $v_{d}$ can be ordered in six different ways, as shown in table 3.1. These inequalities are useful for solving the model and illustrating the results. We can state the following lemma:

Lemma 1. The equilibrium ownership structure and the acquisition price are described in table 3.1: 
Proof. See the Appendix.

Table 3.1: The equilibrium ownership structure and acquisition price.

\begin{tabular}{cccc}
\hline Inequality: & Definition: & Ownership structure: & Acquisition price: \\
\hline$I 1:$ & $v_{m m}>v_{m d}>v_{d}$ & $\mathbf{K}(m)$ & $v_{m m}$ \\
$I 2:$ & $v_{m m}>v_{d}>v_{m d}$ & $\mathbf{K}(m)$ or $\mathbf{K}(d)$ & $v_{m m}$ under $\mathbf{K}(m)$ \\
$I 3:$ & $v_{m d}>v_{m m}>v_{d}$ & $\mathbf{K}(m)$ & $v_{m m}$ \\
$I 4:$ & $v_{m d}>v_{d}>v_{m m}$ & $\mathbf{K}(m)$ & $v_{d}$ \\
$I 5:$ & $v_{d}>v_{m m}>v_{m d}$ & $\mathbf{K}(d)$ &. \\
$I 6:$ & $v_{d}>v_{m d}>v_{m m}$ & $\mathbf{K}(d)$ &. \\
\hline
\end{tabular}

Lemma 1 shows that when one of the inequalities $I 1, I 3$, or $I 4$ holds, $\bar{k}$ is obtained by one of the MNEs. Under $I 1$ and $I 3$, the acquiring MNE pays the acquisition price $\mathcal{A}=v_{m m}$, and $\mathcal{A}=v_{d}$ under $I 4$. When $I_{5}$ or $I_{6}$ holds, the domestic firm keeps its assets. When $I 2$ holds, there exist multiple equilibria. ${ }^{17}$ In the next sections, we shall explore the policy implications of these findings.

\section{Merger policy}

Despite the generally welcoming attitude towards inward FDI among investment liberalizing countries, concerns are raised about the impact of cross-border M\&As on development. Arguments have been put forward, indicating that financial crises allow foreign entrants to acquire domestic firms at "too low" a price or that cross-border M\&As do not increase productive capacity. We address these issues by comparing two government policies: (i) A discriminatory policy which does not allow for cross-border M\&As (henceforth denoted the

${ }^{17}$ An equilibrium where firm $d$ keeps the assets and no MNE posts a bid above $v_{d}$. There is also an equilibrium where one of the MNE's obtains the assets at a price $v_{m m}-\varepsilon$ and another MNE posts the second highest bid at $v_{m m}-2 \varepsilon$. 
D-policy), and (ii) a non-discriminatory policy allowing for cross-border M\&As (henceforth denoted the ND-policy).

The conventional welfare evaluation of M\&As and market structures in an international oligopoly is typically made by comparing the sum of domestic consumer surplus and domestic profits in different market structures. We follow this approach, but add the sales price of firm d's assets into the domestic welfare measure, when the domestic assets are sold. It follows that the $N D$ - and $D$-policies only differ when an MNE acquires the domestic assets $k_{0}$ under the $N D$-policy. Thus, let $P S(l)$ and $C S(l)$ denote the producer and consumer surplus when the ownership of $k_{0}$ is $l=(d, m)$ and let welfare under ownership $l$ be $W(l)=P S(l)+C S(l)$. Defining the difference in welfare $W^{N D-D}=W(m)-W(d)$, and rearranging terms, we obtain:

$$
W^{N D-D}=\left[S^{*}-v_{d}\right]+[C S(m)-C S(d)]
$$

if an acquisition occur under the ND-policy. The first term in (4.15) captures the difference in producer surplus and the second term captures the difference in consumer surplus between the two policies.

\subsection{Foreign acquisition and the acquisition price}

Let us first address the issue of whether foreign entrants acquire domestic firms at "too low" a price by comparing the domestic producer surplus under the discriminatory and non-discriminatory policy. It directly follows that if the assets are sold, the price is higher than the reservation price, i.e. $\mathcal{A} \geq v_{d}=\pi_{d}(d)$. However, as shown in Lemma 1 , the acquisition price will be the maximum of $v_{m m}$ and $v_{d}$, and it may thus be substantially higher than the domestic firm's profit under the discriminatory policy, for two reasons. To illustrate this, note that under I1-I3, if an acquisition take place, the acquisitions price is equal to $v_{m m}$. The difference between the acquisition price, $\mathcal{A}$, and the domestic firm's 
reservation price, $v_{d}$, can then be rewritten as:

$$
\begin{aligned}
\mathcal{A}-v_{d} & =v_{m m}-v_{d} \\
& =\left[\pi_{A}(m)-\pi_{G}(d)-\pi_{d}(d)\right]+\left[\pi_{G}(d)-\pi_{G}(m)\right] .
\end{aligned}
$$

The first term in (4.2) is the asset transfer effect, which includes a rival elimination effect, since there will be one firm less in the host market. However, this effect alone may not generate a surplus. As argued above, it is also likely that the domestic assets are more efficiently used when transferred from domestic to foreign ownership. If this asset complementarity effect is sufficiently large, this will lead to a surplus when the assets are transferred to an acquiring MNE, i.e., $\pi_{A}(m)-\pi_{G}(d)-\pi_{d}(d)>0$. Due to the bidding competition between the MNEs over the domestic assets, this entire surplus is captured by the target firm, i.e. the domestic firm. The second term in (4.2) is the preemption effect. $^{18}$ The profit of a non-acquiring MNE will decrease when the domestic assets are transferred from domestic to foreign ownership, $\pi_{G}(d)>\pi_{G}(m)$, if the domestic assets are used sufficiently more efficiently by an MNE. This implies that an MNE then gains from preventing another MNE from obtaining the assets. Once more, due to the bidding competition between the MNEs, this entire surplus is captured by the domestic firm. Consequently, the producer surplus may be higher, and possibly substantially higher, under the ND-policy.

Moreover, by differentiating (4.2) in the complementarity parameter $\gamma$, and using Assumption 1, we have:

$$
\frac{d\left(\mathcal{A}-v_{d}\right)}{d \gamma}=\frac{d \pi_{A}(m)}{d \gamma}-\frac{d \pi_{G}(m)}{d \gamma}>\frac{d \pi_{A}(m)}{d \gamma}>0
$$

The sales premium, i.e. the sales price net of the domestic profit under the restrictive policy, is thus increasing in $\gamma$ for two reasons: First, the profit for the acquirer increases in $\gamma$ (the asset complementarity effect), which increases the acquisition price. Second, the

\footnotetext{
${ }^{18}$ Fridolfsson and Stennek (1999) and Horn and Persson (2001b) have identified this effect in merger formation models without greenfield investment.
} 
profit of a non-acquirer decreases in $\gamma$ (the preemption effect), since the non-acquirer will then face a stronger competitor in the product market. This implies that the willingness to pay - and thus the acquisition price - increases even further. To summarize:

Proposition 1. (i) The non-discriminatory policy leads to a higher, and possibly significantly higher, domestic producer surplus. (ii) The sales premium, i.e. the sales price net of the domestic profit under the restrictive policy, is non-decreasing and increasing for some parameter values, when the complementarity between the domestic assets and the MNE's firm-specific assets $\gamma$ increases.

In conclusion, due to the asset complementarity effect and the preemption effects, we have found that when a foreign firm acquires a domestic firm, the acquisition price may significantly exceed the profit the domestic firm might attain when keeping the domestic assets. Consequently, it is possible that forbidding cross-border acquisitions could lead to a loss of producer surplus. ${ }^{19}$

\subsection{Foreign acquisitions and the investment pattern}

The second concern over cross-border acquisitions addressed in this paper is that, in contrast to greenfield FDI (i.e. pure new (plant) investment), they do not increase the productive capacity. Greenfield investments are believed to exert larger positive externalities on the rest of the economy by, for instance, strengthening product market competition, thereby leading to large technology spillovers, or educating labor. Consequently, a better understanding of how foreign acquisitions affect the investment pattern seems warranted.

\footnotetext{
${ }^{19}$ Note that the results derived in this section would also hold if the acquisition and greenfield decisions were assumed to take place simultaneously. To see this, note that as long as the domestic assets are scarce and their use by an MNE shifts profits from greenfield investors to the acquiring MNE, $v_{m m}$ might be higher than $v_{m d}$ and $v_{d}$ and thus, the domestic assets will be sold at the price $v_{m m}$. It can also be shown that the acquisition price will still be higher, and possibly substantially higher, than the domestic firm's reservation price, also in an environment with asymmetric firms.
} 
It follows directly from the set-up that the amount of aggregate investment in the market might, indeed, be lower under the non-discriminatory policy, due to the acquisition of the domestic firm. However, it can also be shown that for the acquisition to take place, the MNEs must be sufficiently efficient when using the domestic assets. To see this, note that using Assumption 1 in (2.5)-(2.7) implies that:

$$
\frac{d v_{m m}}{d \gamma}>\frac{d v_{m d}}{d \gamma}>\frac{v_{d}}{d \gamma}=0
$$

since $v_{m m}$ increases through the asset complementarity effect, as well as through the the preemption effect, whereas $v_{m d}$ only increases through the asset complementarity effect. Thus, we have the following Lemma:

Lemma 2. There exists a unique $\gamma^{T}$ defined from $v_{m d}\left(\gamma^{T}, \cdot\right)=v_{d}$ and a unique $\gamma^{P}$ defined from $v_{m m}\left(\gamma^{P}, \cdot\right)=v_{d}$.

We can then derive the following proposition. ${ }^{20}$

Proposition 2. Assume that Assumption A1 holds. Then, (i) if $\gamma<\min \left(\gamma^{T}, \gamma^{P}\right)$ the EOS is $\mathbf{K}(d)$, (ii) If $\gamma>\min \left(\gamma^{T}, \gamma^{P}\right)$, there are two subcases: (a) $\gamma^{T}<\gamma^{P}$. For $\gamma \in\left[\gamma^{T}, \gamma^{P}\right.$ ) the $\operatorname{EOS}$ is $\mathbf{K}(m)$ with $S^{*}=v_{d}$, whereas for $\gamma \geq \gamma^{P}$ the $\operatorname{EOS}$ is $\mathbf{K}(m)$ with $S^{*}=v_{m m}$. (b) $\gamma^{T}>\gamma^{P}$. For $\gamma \in\left[\gamma^{P}, \gamma^{T}\right)$ the EOS is either $\mathbf{K}(m)$ with $S^{*}=v_{m m}$ or $\mathbf{K}(d)$, whereas for $\gamma \geq \gamma^{T}$ the EOS is $\mathbf{K}(m)$ with $S^{*}=v_{m m}$.

Proof: Consider inequalities I1-I6 in table 3.1 and note that Assumption A1 implies that $v_{m d}$ and $v_{m m}$ increase in $\gamma$ and $v_{d}$ is independent of $\gamma$. Case (i): From Lemma 2, it follows that if $\gamma<\min \left(\gamma^{T}, \gamma^{P}\right)$ then I5 or I6 holds. Case (ii): For subcase (a), Lemma 2 implies that I4 arise for $\gamma \in\left[\gamma^{T}, \gamma^{P}\right)$ and that I1 or I3 arise for $\gamma \geq \gamma^{P}$. For subcase (b), Lemma 2 implies that I2 arise for $\gamma \in\left[\gamma^{P}, \gamma^{T}\right)$ and $\gamma>\gamma^{T}$ I1 or I3 arise. QED.

\footnotetext{
${ }^{20}$ It should be noted that in the proof of the is proposition it is presumed that the equilibrium selection in I2 is not affected by level of $\gamma$. If the equilibrium selection was such that foreign acquisitions was the selected equilibrium for low values of $\gamma$ in I2 and no acquisitions the selected equilibrium for high levels of $\gamma$ in I2, our results would not hold.
} 
This implies that there is a counteracting effect to the concentration effect (the domestic firm being bought out), which tends to decrease total capital in the industry, namely, an investment efficiency effect which tends to increase the total capital in the industry through a more efficient use of domestic assets, as well as through sequential investments in new assets. To see this, let $K(m)$ denote the aggregate level of capital when an MNE obtains the domestic asset under the $\mathcal{N D}$-policy, and let $K(d)$ denote the aggregate level of capital under domestic ownership under the $\mathcal{D}$-policy. We then have:

$$
K(m)-K(d)=(\gamma-1) \bar{k}+\left[\sum_{i=1}^{N(m)} \kappa_{i}(m)-\sum_{i=1}^{N(d)} \kappa_{i}(d)\right]
$$

which shows the difference in effective size of existing assets and the difference in aggregate investments in new assets under the two policies. Making use of the symmetry among MNEs, we can decompose (4.5):

$$
K(m)-K(d)=\left[(\gamma-1) \bar{k}+\kappa_{A}(m)-\kappa_{d}(d)\right]-\kappa_{G}(m)+M\left[\kappa_{G}(m)-\kappa_{G}(d)\right]
$$

There are three effects in (4.6): The first term is once more a transaction efficiency effect. It includes a direct effect when the existing domestic assets $\bar{k}$ are placed under MNE ownership, $(\gamma-1) \bar{k}$, but it also includes an indirect effect, $\kappa_{A}(m)-\kappa_{d}(d)$, which tracks the change in investment in new assets $\kappa_{i}$, due to this change in ownership of $\bar{k}$. The second term is the concentration effect, since one less MNE is investing greenfield under a foreign acquisition, $-\kappa_{G}(m)$. Finally, $M\left[\kappa_{G}(m)-\kappa_{G}(d)\right]$, is the preemption effect on the investment behavior of the non-acquiring MNEs, due to the change in ownership of $\bar{k}$.

In the model presented above, it is not possible to derive any unambiguous results on the total effect on dynamic investments and aggregate capital levels of a change in ownership. Thus, to address the second issue in this paper in more detail, i.e. the concern that cross-border M\&As, in contrast to greenfield FDI, do not increase the productive capacity in the country, we need to use a more specific model, which is done in the next section. 


\subsection{The Linear-Quadratic Model}

To examine the effects of foreign acquisition on the investment pattern in more detail, we will apply a Linear-Quadratic model where we can capture that different types of investment have different effects on firms' production costs, which allows to us derive explicit solutions for the optimal behavior by firms in all stages of the game. ${ }^{21}$

We model the oligopoly interaction in period three as Cournot competition in homogenous goods. Investments in new assets in period two (which we may consider as investments in new capital or R\&D) reduce the firm's marginal cost. The profit for firm $i$ can be written (for brevity, omitting function arguments on the right-hand side):

$$
\pi_{i}(\mathbf{q}, \boldsymbol{\kappa}, l)=\left(P-c_{i}\right) q_{i}-\frac{\mu \kappa_{i}^{2}}{2}
$$

where we assume costs to be quadratic in new assets, $\kappa_{i}$, which we henceforth refer to as new capital. Investments in new capital reduce a firm's marginal cost in a linear fashion:

$$
c_{i}=\bar{c}_{i}-\theta \kappa_{i}
$$

where $\theta$ is a positive constant measuring how effectively investments in new capital $\kappa_{i}$ in stage two reduces the marginal cost. For simplicity, we assume that all firms share the same investment technology, $\theta$ and $\mu$. Asymmetries between firms are captured by the intercept term, $\bar{c}_{i}$, which measures the impact on firm $i$ 's absolute efficiency level of the possession of all other assets (such as firm-specific assets or acquired assets) prior to investment in new assets, $\kappa_{i}$, in stage $2 .^{22}$

\footnotetext{
${ }^{21}$ This type of framework, typically modelling an investment game followed by a stage with oligopoly interaction, has been applied in, for example, d'Aspremont and Jacquemin (1988), Leahy and Neary (1997) and Neary (2002). A central difference between the latter two papers and our study, is that our application examines the effects of adding an acquisition game to the third-stage oligopoly- and the second-stage investment interaction.

${ }^{22}$ Assuming that asymmetries between firms enter through the intercept term $\bar{c}_{i}$ in the marginal cost $c_{i}=\bar{c}_{i}-\theta \kappa_{i}$ simplifies the calculations. Alternatively, we could assume that firms differ in their investment costs for new investments $\left(\mu_{i}\right)$, or in how efficiently marginal costs can be reduced by new investments $\left(\theta_{i}\right)$. Qualitatively, this yields similar results.
} 
Making a distinction between firm-types, we have:

$$
\bar{c}_{G}=c, \quad \bar{c}_{A}=c+\tilde{c}_{A}-\gamma \bar{k}, \quad \bar{c}_{d}=c+\tilde{c}_{d}-\bar{k} .
$$

Hence, we assume existing assets $\bar{k}$ and new assets $\kappa_{i}$ to be imperfect substitutes. An acquisition of $\bar{k}$ may, for instance, provide knowledge of the market, or provide access to an existing distribution network, thereby providing assets distinct from new investments $\kappa_{i}$, which provide a capacity to produce. This is modelled by assuming that gaining possession of the domestic assets $\bar{k}$ in stage one alters the intercept term $\bar{c}_{i}$ in (4.8). This is captured by the term $\gamma \bar{k}$ in (4.9), where the complementarity parameter $\gamma$ shows that the efficiency advantages may be larger under MNE ownership (by adding MNEs' firm-specific assets to domestic assets $\bar{k}$ ). However, utilizing older existing assets $\bar{k}$ might also imply less efficient production, as compared to solely investing in new assets (i.e. greenfield entry). This is captured by the term $\tilde{c}_{A} \geq 0 .{ }^{23}$ Similarly, we capture cost asymmetries between MNEs and the domestic firm by including $\tilde{c}_{d} \geq 0$ in the domestic firm's intercept term $\bar{c}_{d}$.

In (4.7), the inverse demand in the product market is given by (4.10):

$$
P=a-\frac{1}{s} \sum_{i=1}^{N} q_{i}
$$

where $a>0$ is a demand parameter, $s$ may be interpreted as the size of the market, $N$ is the total number of firms on the market, i.e. $N(m)=M$ and $N(d)=M+1$ and $q_{i}$ is the quantity supplied by firm $i$.

The game is solved backwards. In period one, firm $i$ maximizes the variable profits $\left(P-c_{i}\right) q_{i}$ such that $(4.11)$ holds:

$$
\frac{\partial \pi_{i}(\boldsymbol{\kappa}, l)}{\partial q_{i}}=P-c_{i}-q_{i}=0
$$

${ }^{23}$ To simplify the presentation, it is assumed that the acquiring MNE will always use its acquired capital in equilibrium. For instance, we could consider this as an acquisition implying a certain location from which relocation is costly. However, while simplifying the exposition, this assumption is not crucial for our results. 
In period two, firm $i$ invests in new capital, $\kappa_{i}$, taking the optimal quantities $\mathbf{q}^{*}(\boldsymbol{\kappa}, l)$ from (4.11) into account. Optimal investment then involves setting:

$$
\frac{d \pi_{i}}{d \kappa_{i}}=\frac{\partial \pi_{i}}{\partial \kappa_{i}}+\sum_{j \neq i}^{N} \frac{\partial \pi_{i}}{\partial q_{j}} \frac{d q_{j}}{d \kappa_{i}}=0,
$$

where the first term is the direct effect, $\frac{\partial \pi_{i}}{\partial \kappa_{i}}=\theta q_{i}-\mu \kappa_{i}$, whereas the second effect is the strategic effect, since an increase in $\kappa_{i}$ affects a rival's output choice, $\frac{d q_{j}}{d \kappa_{i}}$, which, in turn, affects firm $i$ :s profits, $\frac{\partial \pi_{i}}{\partial q_{j}}$. From (4.11), it can be shown that $\frac{d q_{j}}{d \kappa_{i}}=-\frac{s \theta}{N+1}$ and from $\pi_{i}(\boldsymbol{\kappa}, l)$, it follows that $\frac{\partial \pi_{i}}{\partial q_{j}}=-\frac{q_{i}}{s}$. Inserting into (4.12), optimal investments are given from (4.13):

$$
\kappa_{i}^{*}(l)=\frac{\theta}{\mu} q_{i}^{*} \frac{2 N}{N+1},
$$

where we may note the departure from pure cost-minimizing investment captured by the term $\frac{2 N}{N+1}>1 .{ }^{24}$ From $(4.10),(4.11)$ and $(4.13)$, we can solve the Nash-equilibrium in new investments $\boldsymbol{\kappa}^{*}(l)$ and its associated Nash-equilibrium in quantities $\mathbf{x}^{*}(l)$, and then form the reduced-form profits for each type of firm $\pi_{h}(l), h=\{A, G, D\}$, which are given in table A.1 in the Appendix. The reduced form profits $\pi_{h}(l)$, can be inserted into valuations (2.5)-(2.7) to solve the acquisition game in period one, and determine the equilibrium ownership, $l^{*}$. Finally, it will be convenient to define the exogenous variable $\eta \equiv \frac{s \theta^{2}}{\mu}$ measuring the return to investment in capital in the industry.

\subsubsection{Dynamic Investment effects of Cross-border acquisitions}

To examine the impact of cross-border acquisition on aggregate dynamic investments, it is instructive to examine the investment game in period two, using the familiar framework with reaction functions in the $\kappa_{G^{-}} \kappa_{A}$ space, assuming two MNEs, $M=2$. This is done in Figure 4.1, where $R_{h}\left(\kappa_{G}\right)$ is the reaction function of the acquirer $(h=A)$ and the greenfield entrant $(h=G)$, respectively. To illustrate the effects of increasing the complementarity between domestic and foreign assets, we write reaction functions $R_{h}(\gamma)$ and isoprofit-curves

\footnotetext{
${ }^{24}$ Note also that investments $\kappa_{i}$ do not go to zero when the number of firms on the market reach infinity, which means that profits never go to zero.
} 


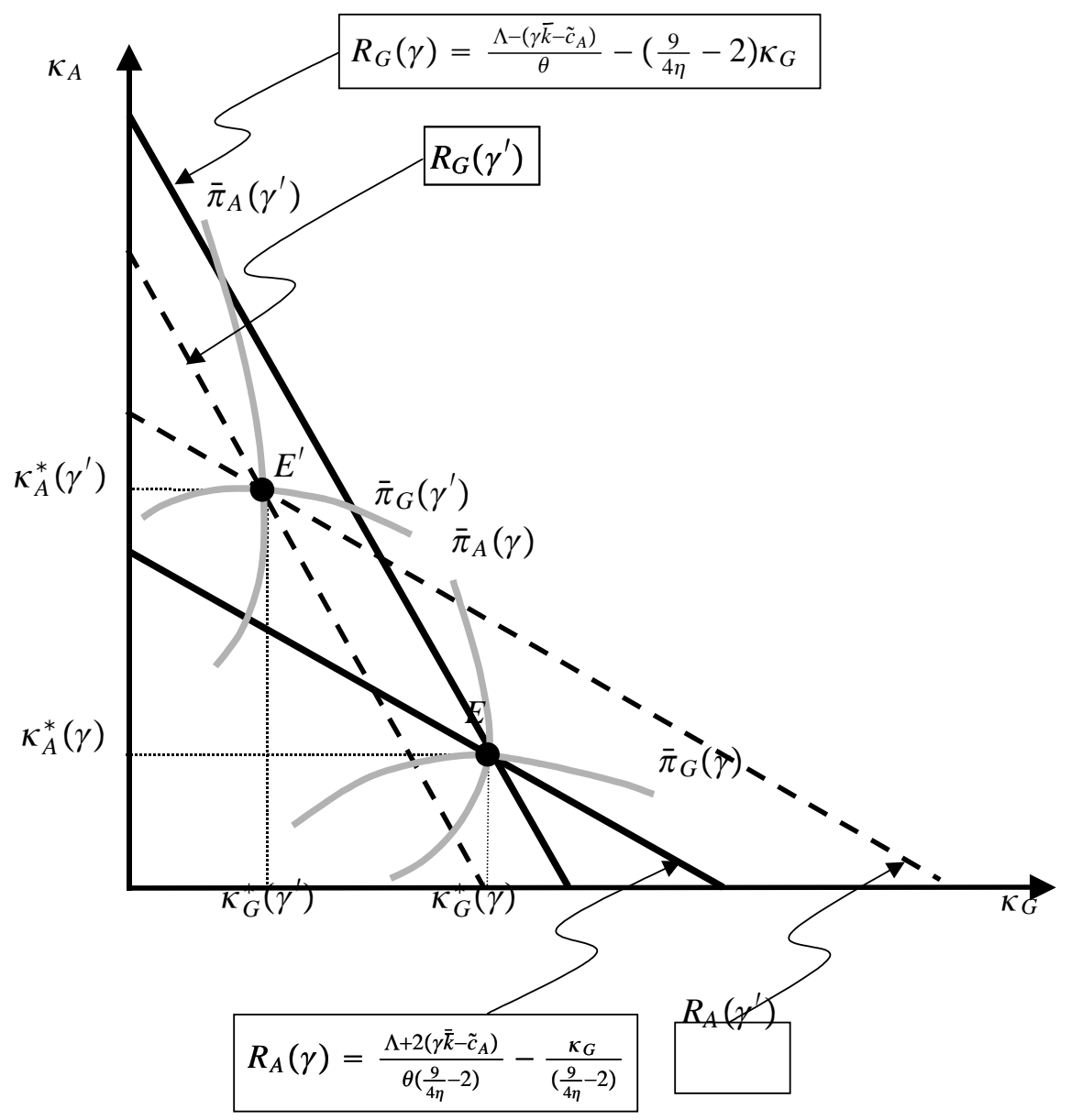

Figure 4.1: Examining optimal new investments for $M=2$ under foreign acquisition.

$\bar{\pi}_{h}(\gamma)$ as dependent on the complementarity parameter $\gamma$, omitting other arguments. Point $E$ then represents the Nash-equilibrium in the investment game giving rise to investments, $\kappa_{h}^{*}(\gamma)$

First, note that an increase in complementarity from $\gamma$ to $\gamma^{\prime}$ shifts $R_{A}(\gamma)$ out to $R_{A}\left(\gamma^{\prime}\right)$, whereas the reaction function of the non-acquiring greenfield entrant moves inwards from $R_{G}(\gamma)$ to $R_{G}\left(\gamma^{\prime}\right)$. This occurs because acquiring complementary assets buys commitment to larger investments in new capital, since the absolute efficiency of the firm increases and $\bar{c}_{A}$ in (4.9) is reduced. ${ }^{25}$ Hence, shifting the equilibrium from $E$ to $E^{\prime}$, the acquirer

\footnotetext{
${ }^{25}$ From (4.8), (4.9) and (4.12), the marginal revenue of new investments is $M R_{\kappa_{A}}=\frac{3}{2} \theta q_{A}$
} which is increasing in $\gamma$, since from (4.11), $q_{A}$ increases in $\gamma$. 
increases its investments by $\Delta \kappa_{A}=\kappa_{A}^{*}\left(\gamma^{\prime}\right)-\kappa_{A}^{*}(\gamma)>0$ (the transaction efficiency effect), whereas the corresponding decrease for the non-acquirer is $\Delta \kappa_{G}=\kappa_{G}^{*}\left(\gamma^{\prime}\right)-\kappa_{G}^{*}(\gamma)<0$ (the preemption effect). As shown in (4.14) below, for the $N$-firm case, the reduction in investments for non-acquirers is smaller than the increase in investments for the acquirer and hence, sequential investments by the acquirer - as well as aggregate investments on the market - simultaneously increase:

$$
\frac{d}{d \gamma}\left[\sum_{i=1}^{N(m)} \kappa_{i}(m)\right]=\frac{s(N+1)}{\left(1+2 N+N^{2}-2 N \eta\right)} \bar{k}>0
$$

where $1+2 N+N^{2}-2 N \eta>0$ is required for a well-behaved equilibrium in the investment game in stage two.

Second, from inspecting the shift of the iso-profits curves, the MNEs' valuation of the domestic assets $v_{m m}$ also increases, as the acquirer's profit increases by $\Delta \pi_{A}=\bar{\pi}_{A}\left(\gamma^{\prime}\right)-$ $\bar{\pi}_{A}(\gamma)>0$ (the asset complementarity effect), whereas the non-acquirer's profit decreases by $\Delta \pi_{G}=\bar{\pi}_{G}\left(\gamma^{\prime}\right)-\bar{\pi}_{G}(\gamma)<0$ (the preemption effect). Since an MNEs' valuation of the domestic assets $v_{m d}$ only increases by $\Delta \pi_{A}$, which is less than the increase in $v_{m m}$, and $v_{d}$ is not affected, Figure 4.1 also illustrates Proposition 2, thereby implying that foreign acquisitions tend to occur when the complementarity between MNEs firm-specific assets and the domestic asset $\gamma$ is sufficiently large.

From (4.4), (4.5) and (4.14), we can state the following proposition:

Proposition 3. In the Linear-Quadratic Model: (i) foreign acquisitions occur when the complementarity between the domestic assets and the MNE's firm-specific assets $\gamma$ is sufficiently large. (ii) The amount of sequential investments in new assets by the acquirer, as well as aggregate investments in new assets, increase in the complementarity parameter $\gamma$

\subsubsection{Welfare and investments}

Having examined the effects on aggregate investments of cross-border acquisition, we will now turn to the implications for welfare. The conventional welfare evaluation of M\&As 
and market structures in an international oligopoly is typically made by comparing the sum of domestic consumer surplus and domestic profits in different market structures. Here, we follow this approach, but add the sales price of firm d's assets in the domestic welfare measure, when the domestic assets are sold. It follows that the $\mathcal{N D}$ - and $\mathcal{D}$ policies only differ when an MNE acquires the domestic assets $\bar{k}$ under the $\mathcal{N} \mathcal{D}$-policy, i.e. whenever one of the inequalities $I 1-I 4$ holds. Once more, let $W_{\mathcal{N D}}=W(m)$ denote the welfare level when an MNE obtains the domestic asset under the ND-policy, and let $W_{\mathcal{D}}=W(d)$ denote the welfare level under the $\mathcal{D}$-policy. Defining the difference in welfare $W_{\mathcal{N D}-\mathcal{D}}=W(m)-W(d)$, and rearranging terms, we obtain:

$$
W_{\mathcal{N D}-\mathcal{D}}=\left[\mathcal{A}-\pi_{d}(d)\right]+[C S(m)-C S(d)]
$$

where $\mathcal{A}$ is the acquisition price of assets $\bar{k}, \pi_{d}(d)$ is the domestic firm's profit, $C S(d)$ the consumer surplus under domestic ownership of $\bar{k}$, and $C S(m)$ the consumer surplus under foreign ownership of $\bar{k}$. The first term in (4.15) captures the difference in producer surplus and the second term captures the difference in consumer surplus between the two policies.

In Figure 4.2(i) and (iv), we illustrate how the relationship between cross-border acquisitions and aggregate investments in new capital depends on the complementarity parameter $\gamma$ and the variable $\eta \equiv \frac{s \theta^{2}}{\mu}$ measuring the return to investment in capital in the industry. We may note that acquisitions first occur at the reservations price $\mathcal{A}=v_{d}$. In such cases, MNEs have roughly the same ability in using the domestic firm' assets $\bar{k}$ (i.e. $\gamma \approx 1$ ) and foreign acquisitions mainly occur for anti-competitive reasons. However, consistent with Proposition 3, Figure 4.2(i) also shows that the bidding competition among MNEs to gain the advantage of being the acquirer (the asset complementarity effect) and also avoiding the disadvantage of being the non-acquirer (the preemption effect), ensures that foreign acquisitions start emerging when the MNEs are more efficient in using the domestic assets $\bar{k}$ and that increases in complementarity $\gamma$ (and, to some lesser extent, increases in the return to investment, $\eta$ ) quickly bid up the acquisition price to $\mathcal{A}=v_{m m}$. Once more, consistent with Proposition 3, Figure 4.2(iv) then illustrates that when MNEs 


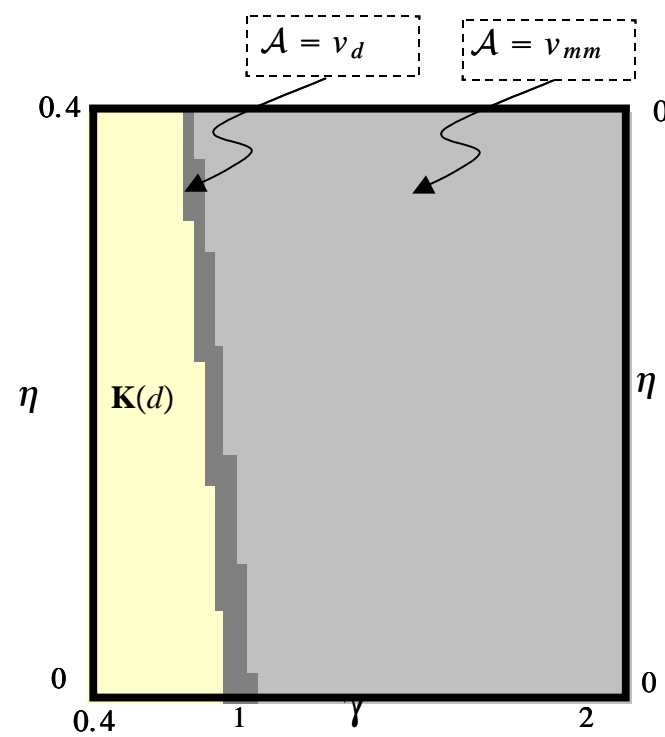

(i) EOS and acquisition price

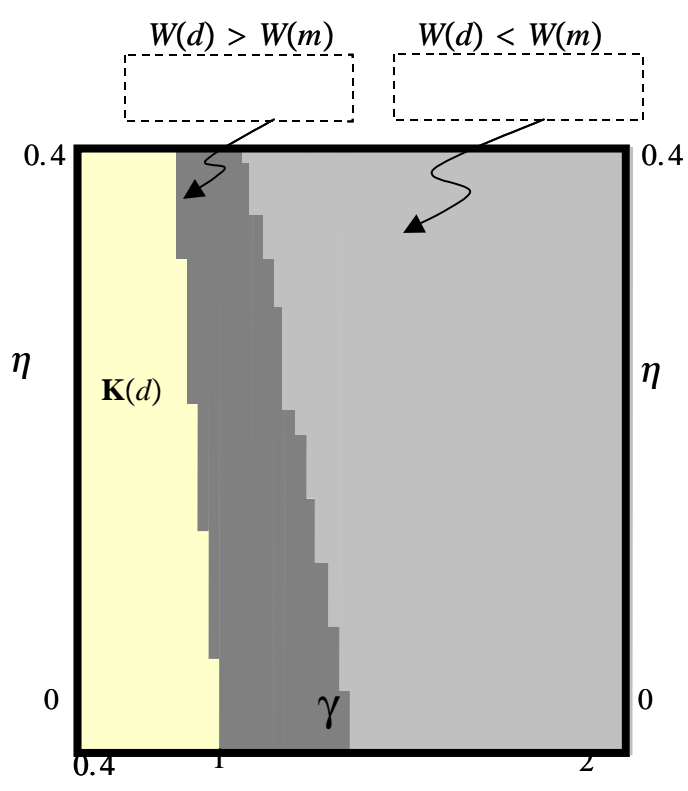

(iii) Welfare

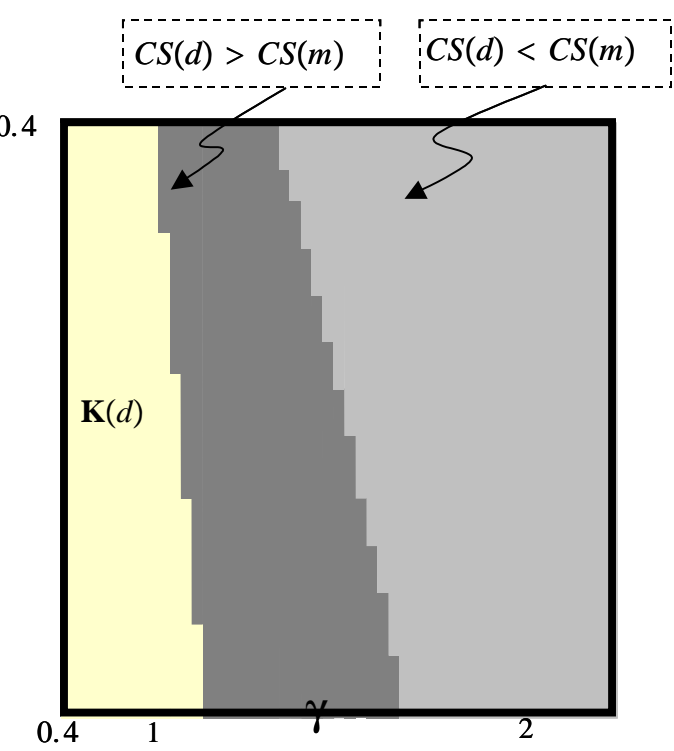

(ii) Consumer surplus $\sum_{i=1}^{N(d)} \kappa_{i}(d)>\sum_{i=1}^{N(m)} \kappa_{i}(m) \sum_{i=1}^{N(d)} \kappa_{i}(d)<\sum_{i=1}^{N(m)} \kappa_{i}(m)$

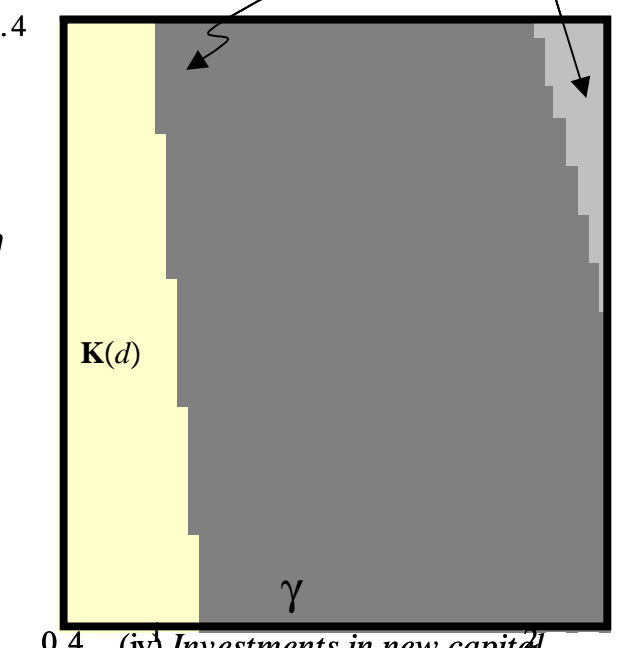

(iv) Investments in new capital

Figure 4.2: Examing the welfare effects of a cross-border acquisition in the Linear Quadratic Model, when varying the complementarity $\gamma$ and return to investments $\eta \equiv \frac{s \theta^{2}}{\mu}$. Other parameters set at $\Lambda=5, s=5, M=4, \bar{k}=1, \tilde{c}_{A}=0.5$ and $\tilde{c}_{d}=0.8$. 
are sufficiently more efficient and the return to new investments is sufficiently high, aggregate investment into new capital is larger under the non-discriminatory policy. We may, however, note that the latter region is limited in size, due to the concentration effect noted in (4.6).

Next, we turn to consumer effects. To evaluate how investments affect consumer welfare, we need to take into account how aggregate capital changes with ownership, i.e. we need to account for both the direct efficiency effect on domestic assets (the first term in (4.5)), as well as the indirect effect on new investments (the second term in (4.5)), since both effects will affect firms' output choices. Once more, consistent with Proposition 3, Figure 4.2(ii) shows the region where consumers gain from the non-discriminatory policy to be conducive to high levels of complementarities and high returns to investments. This said, at low levels of complementarity low returns to investments, we may note that anti-competitive foreign acquisitions occur, thereby hurting consumers. Finally, considering total welfare and adding the acquisition price to the consumer surplus, there is an increase in the region where non-discriminatory policy is preferred. The reason is that, in equilibrium, and as shown in proposition 1, the producer surplus is always higher or substantially higher under the non-discriminatory policy. To summarize

Proposition 4. In the Linear-Quadratic Model: (i) restricting cross-border acquisitions will reduce the domestic producer surplus and the consumer surplus when $\gamma$ and $\eta$ are sufficiently high, since cross-border acquisitions lead to a more efficient use of existing capital as well as sequential new investments. (ii) restricting cross-border acquisitions will increase the domestic consumer surplus when $\gamma$ and $\eta$ are sufficiently low, since crossborder acquisitions lead to a lower level of new investments and increase the concentration.

Consequently, we demonstrate that asset complementarities in acquisitions and the associated dynamic investment effects are important for determining the welfare effects of cross-border M\&As. 


\section{Extensions}

In order to illuminate the mechanisms identified in a simple way we have abstracted from several potentially important aspects of FDI for the host country. Below we address some of these issues, namely, effects of endogenous entry and exit and effects of having more domestic firms in the host market.

\subsection{Entry and exit}

So far in the analysis, we have assumed that all $M$ MNEs invest. If complementarities create a strong acquirer, greenfield entry may be reduced, however. We will here explore entry effects in the Linear-Quadratic Model. To this end, we assume that greenfield entry takes place until the last firm cannot cover its investment costs, that is, the total number of firms on the market $N$ must fulfill $\pi_{G}(N(l))>\mathcal{G}$ and $\pi_{G}(N(l)+1) \leq \mathcal{G}$, where $\mathcal{G}$ is the fixed cost of entry in addition to the investments costs in period two, and where reducedform profit indicates the number of firms in the market. The probability of successful greenfield entry $\mathrm{p}(l)$ is then:

$$
\mathrm{p}(l)= \begin{cases}\frac{N(m)-1}{M-1} & \text { if } \quad l=m \\ \frac{N(d)-1}{M} & \text { if } l=d .\end{cases}
$$

An MNE's probability of greenfield entry may not be the same under a different ownership of the domestic assets: First, the number of MNEs competing for greenfield entry is different. In addition, the number of profitable greenfield entrants $(N(l)-1)$ may not be the same. Introducing uncertainty in greenfield entry, we then need to adjust firms' valuations of the domestic assets. These valuations now become $v_{m m}=\pi_{A}(m)-\mathrm{p}(m)\left[\pi_{G}(m)-\mathcal{G}\right]$, $v_{m d}=\pi_{A}(m)-\mathrm{p}(d)\left[\pi_{G}(d)-\mathcal{G}\right]$ and, finally, $v_{d}=\pi_{d}(d)$, where we have omitted the number of firms as an argument.

The results presented in Figure 5.1 are qualitatively very similar to the previous results obtained in Figure 4.2. In Figure 5.1(i), we see that competition for the market (i.e. entry) further increases the bidding competition among MNEs, which tends to increase the region 
where the acquisition price is $\mathcal{A}=v_{m m}$.

In Figure 5.1(ii), the consumer surplus effects of the different policies are depicted. For a given equilibrium number of entrants, consumers gain from foreign ownership of the domestic assets when the complementarity $\gamma$ and the return to investments $\eta$ are sufficiently high. However, more efficient acquisitions (larger $\gamma$ ) can also lead to fewer MNEs entering greenfield, as illustrated in Figure 5.1(iv), thereby reducing the consumer surplus. Consumers could then be better or worse off under a non-discriminatory policy, depending on the details in the firm and product market characteristics.

Considering total welfare, adding the acquisition price to the consumer surplus, Figure 5.1(iii) shows that the region where the discriminatory policy is preferred now becomes much smaller. The reason is, once more, that the producer surplus is always higher or substantially higher under the non-discriminatory policy, where this effect is reinforced when MNEs also bid for safe entry into the market.

Forbidding cross-border acquisition may also cause an exit of the domestic firm as shown in the following proposition

Proposition 5. Under the discriminatory policy, the domestic firm exits if the return to investment in new assets is sufficiently high, i.e. if $\eta>\eta^{*}=\frac{N+1}{2 N}\left(\frac{\Lambda-N \hat{c}_{d}}{\Lambda-\hat{c}_{d}}\right)$.

Hence, it is shown that under the discriminatory policy, the domestic firm might be forced out of the market due to competition from the potentially more efficient greenfield entering MNEs. However, the domestic assets might be valuable for the MNEs and a crossborder M\&A would take place if allowed. Consequently, a restrictive cross-border M\&A policy might cause the exit of domestic producers, and an exit without any compensation.

In conclusion, our main finding that producer surplus and total surplus tend to be higher under the non-discriminatory policy also holds when entry is endogenous. However, the effects on consumers are more involved when endogenizing entry. 


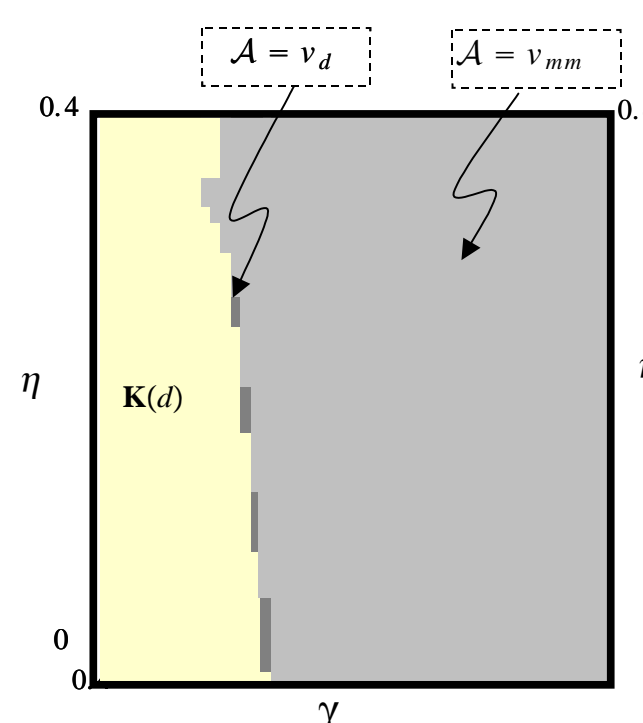

(i) EOS and acquisition price

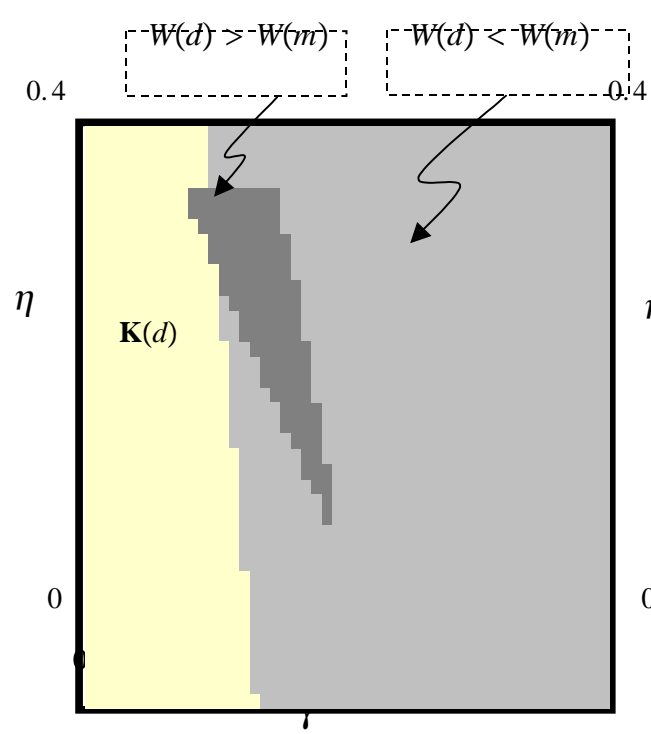

(iii) Welfare

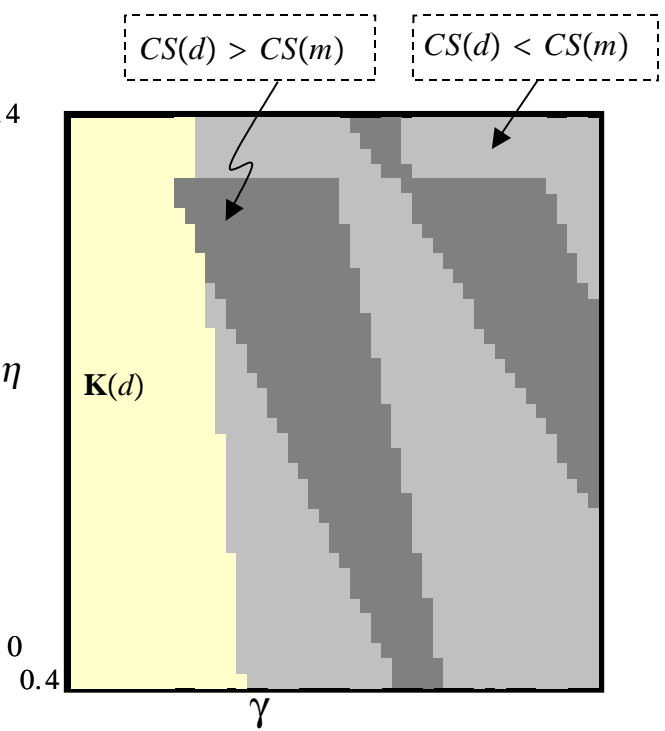

(ii) Consumer surplus

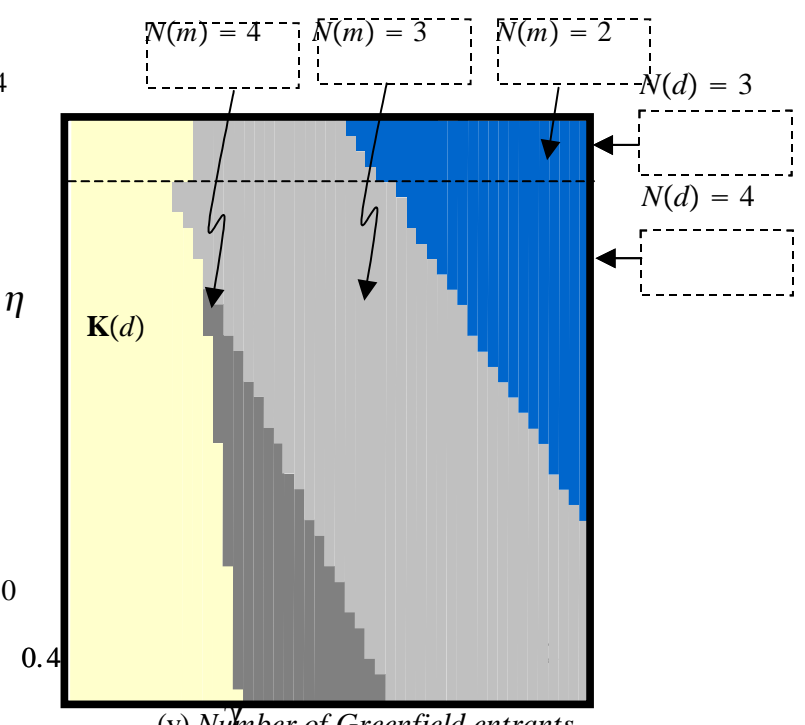

(v) Number of Greenfield entrants

Figure 5.1: Welfare effects of cross-border acquisition in the Linear Quadratic Model under endogenous entry, when varying complementarity $\gamma$ and return to investments $\eta \equiv \frac{s \theta^{2}}{\mu}$. Other parameters set at $\Lambda=5, s=5, M=5, \bar{k}=1, \tilde{c}_{A}=0.5, \tilde{c}_{d}=0.8$ and $\mathcal{G}=5$. 


\subsection{More domestic firms}

We have restricted the analysis to have only one domestic firm. Extending our analysis to more domestic firms give rise to at least two new important aspects for the question addressed here, namely, (i) externalities (positive or negative ) on non-selling domestic firms and (ii) the "bargaining position" of the selling domestic firm.

Let us start with the effects on the non-selling domestic firms profits. To this end we now assume that we have several other domestic firms in the market. They are assumed not to be for sale. An efficiency enhancing acquisition might then reduce these firms profits and might thus imply that the domestic producer surplus fall under a non-discriminatory policy. However, it can be shown in a version of the Linear-Quadratic Model with more than one domestic firm that the selling premium dominates this effect for many parameter values. $^{26}$

Let us now turn to the effect on the "bargaining position of the selling domestic firm. A crucial assumption is that the domestic assets are unique, i.e. there are no other domestic firms. Will the results in the paper hold if this assumption is relaxed? Our analysis seems valid for situations where the domestic assets are sufficiently scarce. For instance, the results derived here would hold if we had a smaller number of domestic firms, denoted $D$, than MNEs, denoted $M$, and each of the domestic firm's assets were auctioned out sequentially, and assuming that it would be profitable for an MNE to buy one domestic asset only. The analysis presented above would then apply when the assets of the last domestic firm are sold out, etc.

If there were more domestic firms than MNEs, the situation might be different. Assume that a domestic firm cannot make positive profits when the MNEs have entered. Then, in the last period, if there are two domestic firms left, the remaining MNE could play them out against each other, buying the assets at a price close to zero. In the second last period, the price will be determined in the same fashion and hence, the acquisition price for any

\footnotetext{
${ }^{26}$ Proofs are available upon request.
} 
of the assets will be close to zero. Thus the scarcity of the domestic assets are crucial for our result on domestic seller premium.

\section{Concluding remarks}

In this paper, we have shown that investment liberalizing countries might forego the possibility of mergers and acquisitions (M\&A) that would significantly increase welfare when having restrictions on cross-border M\&As. The first reason is that combining multinational enterprises' (MNEs') strong firm-specific assets with domestic firms' important countryspecific assets would mean a possibility of creating a surplus for the firms involved. If the domestic assets provide the acquirer with a strong position in the host market relative to other MNEs, MNEs gain from preventing other MNEs from obtaining the assets, thereby further increasing the surplus. Then, we have shown that if domestic assets are sufficiently scarce, the selling domestic firm will capture the created surplus. The second reason is that for the acquisition to take place, the MNE must be sufficiently efficient when using the domestic assets and invest sufficiently sequentially. This implies that the amount of productive capacity in the market, and thereby the consumer surplus, will be higher under the non-discriminatory policy in many situations.

These findings suggest that competition policy, but not a discriminatory policy towards foreigners, might play an important role in liberalized markets. Moreover, it seems important that the authority ensures that there is competition for entering the liberalized markets, both as acquirers and greenfield entrants. Consequently, measures to reduce the pre-investment cost for owners contemplating investment in the liberalized market in general seem warranted.

To empirically determine when there is scarcity on the seller side when countries investment liberalize is crucial for the selling surplus effect identified in this paper. An indication of the mechanisms identified here being empirically relevant could be found in the empirical event study literature on M\&A performance. There, it is found that target 
share holders benefit from a merger, whereas the bidding firms' share holders generally break even (see Scherer and Ross, 1990).

\section{A. Appendix:}

\section{A.1. Proof of Lemma 1}

First, note that $b_{i} \geq \max v_{m l}, l=\{\mathrm{d}, \mathrm{m}\}$ is a weakly dominated strategy, since no MNE will post a bid equal to or above its maximum valuation of obtaining the assets and that firm $d$ will accept a bid in stage 2 , iff $b_{i}>v_{d}$.

Inequality $\mathbf{I} 1$ Consider the equilibrium candidate $\mathbf{b}^{*}=\left(b_{1}^{*}, b_{2}^{*}, \ldots\right.$, yes $)$. Let us assume that MNE $w \neq d$ is the MNE that has posted the highest bid and obtains the assets and firm $s \neq d$ the MNE with the second highest bid.

Then, $b_{w}^{*} \geq v_{m m}$ is a weakly dominated strategy. $b_{w}^{*}<v_{m m}-\varepsilon$ is not an equilibrium, since firm $j \neq w, d$ then benefits from deviating to $b_{j}=b_{w}^{*}+\varepsilon$, since it will then obtain the assets and pay a price lower than its valuation of obtaining them. If $b_{w}^{*}=v_{m m}-\varepsilon$, and $b_{s}^{*} \in\left[v_{m m}-\varepsilon, v_{m m}-2 \varepsilon\right]$, then no MNE has an incentive to deviate. By deviating to $n o$, firm $d$ 's payoff decreases since it foregoes a selling price exceeding its valuation, $v_{d}$. Accordingly, firm $d$ has no incentive to deviate and thus, $\mathbf{b}^{*}$ is a Nash equilibrium.

Let $\mathbf{b}=\left(b_{1},,, b_{m}, n o\right)$ be a Nash equilibrium. Let MNE $h$ be the MNE with the highest bid. Firm $d$ will then say no iff $b_{h} \leq v_{d}$. But MNE $j \neq d$ will have the incentive to deviate to $b^{\prime}=v_{d}+\varepsilon$ in period 1 , since $v_{m d}>v_{d}$. This contradicts the assumption that $\mathbf{b}$ is a Nash equilibrium.

Inequality $\mathbf{I} 2$ Consider the equilibrium candidate $\mathbf{b}^{*}=\left(b_{1}^{*}, b_{2}^{*}, \ldots, y\right)$. Then, $b_{w}^{*} \geq v_{i j}$ is a weakly dominated strategy. $b_{w}^{*}<v_{i j}-\varepsilon$ is not an equilibrium since firm $j \neq w, d$ then benefits from deviating to $b_{j}=b_{w}^{*}+\varepsilon$, since it will then obtain the assets and pay a price lower than its valuation of obtaining them. If $b_{w}^{*}=v_{m m}-\varepsilon$, and $b_{s}^{*} \in\left[v_{m m}-\varepsilon, v_{m m}-2 \varepsilon\right]$, 
then no MNE has an incentive to deviate. By deviating to no, firm d's payoff decreases since it foregoes a selling price exceeding its valuation, $v_{d}$. Accordingly, firm $d$ has no incentive to deviate and thus, $\mathbf{b}^{*}$ is a Nash equilibrium.

Consider the equilibrium candidate $\mathbf{b}^{* *}=\left(b_{1}^{* *}, b_{2}^{* *}, \ldots, n o\right)$. Then, $b_{w}^{*} \geq v_{d}$ is not an equilibrium since firm $d$ would then benefit by deviating to yes. If $b_{w}^{*}<v_{d}$, then no MNE has an incentive to deviate. By deviating to yes, firm d's payoff decreases since it then sells its assets at a price below its valuation, $v_{d}$. Firm $d$ has no incentive to deviate and thus, $\mathbf{b}^{* *}$ is a Nash equilibrium.

Inequality I3 Consider the equilibrium candidate $\mathbf{b}^{*}=\left(b_{1}^{*}, b_{2}^{*}, \ldots\right.$, yes $)$. Then, $b_{w}^{*} \geq v_{m m}$ is a weakly dominated strategy. $b_{w}^{*}<v_{m m}-\varepsilon$ is not an equilibrium since firm $j \neq w, d$ then benefits from deviating to $b_{j}=b_{w}^{*}+\varepsilon$, since it will then obtain the assets and pay a price lower than its valuation of obtaining them. If $b_{w}^{*}=v_{m m}-\varepsilon$, and $b_{s}^{*} \in\left[v_{m m}-\varepsilon, v_{m m}-2 \varepsilon\right]$, then no MNE has an incentive to deviate. By deviating to no, firm d's payoff decreases, since it foregoes a selling price exceeding its valuation $v_{d}$. Accordingly, firm $d$ has no incentive to deviate and thus, $\mathbf{b}^{*}$ is a Nash equilibrium.

Let $\mathbf{b}=\left(b_{1}, \ldots, b_{M}, n o\right)$ be a Nash equilibrium. Firm $d$ will then say no iff $b_{h} \leq v_{d}$. But MNE $j \neq d$ will then have the incentive to deviate to $b^{\prime}=v_{d}+\varepsilon$ in stage 1 , since $v_{m d}>v_{d}$. This contradicts the assumption that $\mathbf{b}$ is a Nash equilibrium.

Inequality $\mathbf{I}$ Consider the equilibrium candidate $\mathbf{b}^{*}=\left(b_{1}^{*}, b_{2}^{*}, \ldots\right.$, yes $)$. Then, $b_{w}^{*}>v_{d}$ is not an equilibrium since firm $w$ would then benefit from deviating to $b_{w}=v_{d}$. $b_{w}^{*}<v_{d}$ is not an equilibrium, since firm $d$ would then not accept any bid. If $b_{w}^{*}=v_{d}-\varepsilon$, then firm $w$ has no incentive to deviate. By deviating to $b_{j}^{\prime} \leq b_{w}^{*}$, firm $j^{\prime}$ 's, $j \neq w, d$, payoff does not change. By deviating to $b_{j}^{\prime}>b_{w}^{*}$, firm $j$ 's payoff decreases since it must pay a price above its willingness to pay $v_{m m}$. Accordingly, firm $j$ has no incentive to deviate. By deviating to $n o$, firm d's payoff decreases since it foregoes a selling price above its valuation $v_{d}$. Accordingly, firm $d$ has no incentive to deviate and thus, $\mathbf{b}^{*}$ is a Nash equilibrium. 
Let $\mathbf{b}=\left(b_{1},, b_{m}, y e s\right)$ be a Nash equilibrium. If $b_{w} \geq v_{m m}$, then firm $w$ will have the incentive to deviate to $b^{\prime}=b_{w}-\varepsilon$. If $b_{w}<v_{m m}$, then firm $d$ will have the incentive to deviate to no, which contradicts the assumption that $\mathbf{b}$ is a Nash equilibrium.

Let $\mathbf{b}=\left(b_{1}, \ldots, b_{m}, n o\right)$ be a Nash equilibrium. Firm $d$ will then say no iff $b_{h} \leq v_{d}$. But MNE $j \neq d$ will have the incentive to deviate to $b^{\prime}=v_{d}+\varepsilon$ in stage 1 since $v_{m d}>v_{d}$, which contradicts the assumption that $\mathbf{b}$ is a Nash equilibrium.

Inequalities I5 or I6 Consider the equilibrium candidate $\mathbf{b}^{*}=\left(b_{1}^{*}, b_{2}^{*}, \ldots, n o\right)$, where $b_{i}^{*}<v_{d} \forall i \in M$. It then follows directly that no firm has an incentive to deviate and thus, $\mathbf{b}^{*}$ is a Nash equilibrium.

Then, note that firm $d$ will accept a bid iff $b_{i} \geq v_{d}$. But $b_{i} \geq v_{d}$ is a weakly dominating bid in these intervals, since $v_{d}>\max \left\{v_{m m}, v_{m d}\right\}$. Thus, the assets will not be sold in these intervals.

\section{A.2. The Linear Quadratic Model}

Quantities and profits (as a function of the ownership of the domestic assets, $l$ ) in the Linear Quadratic Model are given in table A.1, below. 
Table A.1: Optimal quantities as functions of ownership structure.

\begin{tabular}{|c|c|c|}
\hline & Domestic ownership & Foreign ownership \\
\hline$l:$ & $d$ & $m$ \\
\hline$\pi_{h}(l):$ & $\frac{1}{s} q_{h}^{2}(d)\left[1-\frac{2 \eta}{9}\right]$ & $\frac{1}{s} q_{h}^{2}(m)\left[1-\frac{2 \eta}{9}\right]$ \\
\hline$N(l):$ & $M+1$ & $M$ \\
\hline$q_{A}(l):$ & & $\frac{s(N+1)\left[\Lambda(1+N-2 N \eta)-N \hat{c}_{A}(1+N-2 \eta)\right]}{(1+N-2 N \eta)\left(1+2 N+N^{2}-2 N \eta\right)}$ \\
\hline$q_{G}(l):$ & $\frac{s(N+1)\left[\Lambda(1+N-2 N \eta)+\hat{c}_{d}(N+1)\right]}{(1+N-2 N \eta)\left(1+2 N+N^{2}-2 N \eta\right)}$ & $\frac{s(N+1)\left[\Lambda(1+N-2 N \eta)+\hat{c}_{A}(N+1)\right]}{(1+N-2 N \eta)\left(1+2 N+N^{2}-2 N \eta\right)}$ \\
\hline$q_{d}(l):$ & $\frac{s(N+1)\left[\Lambda(1+N-2 N \eta)-N \hat{c}_{d}(1+N-2 \eta)\right]}{(1+N-2 N \eta)\left(1+2 N+N^{2}-2 N \eta\right)}$ & \\
\hline Note: & $\eta \equiv \frac{s \theta^{2}}{\mu}, \quad \Lambda \equiv a-c, \quad \hat{c}_{A}$ & $\tilde{c}_{A}-\gamma \bar{k}, \quad \hat{c}_{d} \equiv \tilde{c}_{d}-\bar{k}$ \\
\hline
\end{tabular}

\section{References}

[1] Aitken, B. and Harrison, A., 1999, Do Domestic Firms Benefit from Direct Foreign Investment? Evidence from Venezuela", American Economic Review, Vol. 89 NO. 3, 605-618.

[2] d'Aspremont, C. and A. Jacquemin, 1988, "Cooperative and noncooperative R\&D in duopoly with spillovers," American Economic Review, 78(5), 1133-1137.

[3] Business Week, April 23 2001, October 2 2000, November 202000.

[4] Caves, R.E., 1996. Multinational Enterprise and Economic Analysis. 2nd edition, (Cambridge University Press, Cambridge and New York).

[5] Falvey, R., 1998, "Mergers in open economies, "The World Economy, 21, 1061-1076. 
[6] Fridolfsson, S.-O. and J. Stennek, 1999, Why Mergers Reduce Profits, and Raise Share Prices, Working Paper No. 511, (Stockholm: The Research Institute of Industrial Economics).

[7] Head K, and J. Reis, 1997, "International Mergers and Welfare under Decentralized Competition Policy", Canadian Journal of Economics v30, n4: 1104-23.

[8] Horn, H. and L. Persson, 2001, "The Equilibrium Ownership of an International Oligopoly," Journal of International Economics, Vol. 53, No. 2.

[9] Horn, H. and L. Persson, 2001, "Endogenous Mergers in Concentrated Markets," International Journal Of Industrial Organization, Vol. 19, 1213-1244.

[10] Kamien, M. I. and Zang, I., 1990, "The Limits of Monopolization Through Acquisition," Quarterly Journal of Economics, 2, 465-99.

[11] Klimenko M. and Saggi K., 2005, "Technical compatibility and the mode of foreign entry with network externalities, Mimeo Georgia Institute of Technology, Atlanta.

[12] Leahy, D. and P. Neary, 1997, "Public policy towards R\&D in oligopolistic industries," American Economic Review, 87:4, 642-662.

[13] Lipsey, R. E., 2000, Interpreting developed countries' foreign direct investmens, NBER Working Paper 7810.

[14] Lommerud, K.E., Straume O.R. and Sorgard, L., 2004, "National versus international mergers in unionized oligopoly," Mimeo, Norwegian School of Economics and Business Administration, Bergen.

[15] Markusen, J. R., 1995, The Boundaries of Multinational Enterprises and the Theory of International Trade, Journal of Economic Perspective 9, 169-189.

[16] Markusen, J. R., 1997, Trade vs. Investment Liberalization, National Bureau of Economic Research Working Paper: 6231 October. 
[17] Mattoo A., Olarrega M., and Saggi K., 2004, "Mode of foreign entry, technology transfers, and FDI policy, Journal of Development Economics, 75, 95-111.

[18] Neary, J. P, 2002 "Foreign competition and wage inequality", Review of International Economics, 10:4, 680-693.

[19] Neary, J. P., 2003, "Cross-border mergers as instruments of comparative advantage," Mimeo, University College Dublin.

[20] Norbäck, P. J. and Persson, L., 2002, "Investment Liberalization-Who benefits from cross-border mergers and acquisitions?, CEPR Discussion papers series No. 3166.

[21] Norbäck, P. J. and Persson, L., 2004, "Privatization Policy in an International Oligopoly," Economica,forthcoming.

[22] Perry, Martin K. and Porter, Robert H., "Oligopoly and the Incentive for Horizontal Merger," American Economic Review, 1985, 75, 219-27.

[23] Scherer, F. M., and Ross, D., 1990, "Industrial Market Structure and Economic Performance," Houghton Mifflin Company.

[24] UNCTAD, World Investment Report 2000, (United Nations Conference on Trade and Development, Geneva). 